\title{
METASTATIC NON-SMALL CELL LUNG CANCER IN BRAZIL: TREATMENT HETEROGENEITY IN ROUTINE CLINICAL PRACTICE
}

Fauzia F. Naime ${ }^{1}$, Riad Naim Younes ${ }^{2}$, Bruno G. Kersten ${ }^{3}$, Agnaldo Anelli ${ }^{4}$, Carlos Augusto M. Beato ${ }^{3}$, Rogério M. Andrade ${ }^{1}$, Marcella P. Carrara ${ }^{1}$, Jefferson Luiz Gross $^{2}$

Naime FF, Younes RN, Kersten BG, Anelli A, Beato CAM, Andrade RM, Carrara MP, Gross JL. Metastatic non-small cell lung cancer in Brazil: treatment heterogeneity in routine clinical practice. Clinics. 2007;62(4):397-404.

\begin{abstract}
Lung cancer is one of the main causes of cancer related deaths. Approximately three quarters of these tumors are non-small cell carcinomas. When diagnosed the majority of patients show the disease locally advanced or metastatic. The chemotherapy is the chosen therapy for patients with advanced lung cancer. The majority of published studies with chemotherapy are performed in academic centers under a strict control of research protocols.

PURPOSE: The aim of this study is to evaluate the usual management of metastatic NSCLC patients outside of a clinical trial setting in three different oncologic centers in Brazil.

METHODS: This is a retrospective study of patients with metastatic non-small cell lung cancer admitted for treatment in three different Cancer Centers in Brazil. 564 patients from Brazilian public heath system and private/health insurance system were considered for the present study.

RESULTS: Among 564 patients in this study, 335 (59.4\%) received chemotherapy. For all patients, 47 different regimens of chemotherapy were identified. The median follow-up time was eight months and the overall median survival of all patient population submitted to chemotherapy was 9.7 months.

DISCUSSION: There was a great heterogeneity in the regimens of drugs to treat metastatic NSCLC patients. The overall survival was significantly better for patients treated with first line chemotherapy compared to patients that only received best supportive care. Results of prospective randomized clinical trials should be carefully analyzed before transferred to the daily clinical practice.
\end{abstract}

KEY WORDS: Lung Cancer. Non Small Cell Lung Cancer (NSCLC). Metastases. Chemotherapy. Routine clinical practice.

\section{INTRODUCTION}

Lung cancer is the second most common cancer, and the leading cause of cancer death in the United States of America. There are over 160.000 new cases each year in

${ }^{1}$ Instituto Paulista de Cancerologia - Department of Clinical Oncology- São Paulo/SP, Brazil

${ }^{2}$ Hospital AC Camargo - Department of Thoracic Surgery-São Paulo/SP, Brazil ${ }^{3}$ Hospital Amaral Carvalho de Jaú. Department of Clinical Oncology- Jaú/ SP, Brazil

${ }^{4}$ Grupo Paulista de Oncologia Integrada - Department of Clinical OncologySão Paulo/SP, Brazil

Email: fauzianaime@yahoo.com.br

Received for publication on January 23, 2007

Accepted for publication on March 27, 2007 that country and estimated overall 5-year survival remains at $15 \%$. One of the reasons for this poor survival is that $39 \%$ of patients had advanced disease at diagnosis ${ }^{1}$. The INCA (National Institute of Cancer) in Brazil estimates that 27.000 new cases of NSCLC will be diagnosed in 2006 among Brazilians ${ }^{2}$. The most common histological types are squamous cell carcinoma, adenocarcinoma, and large cell carcinoma. As approaches to treatment are similar, these histological types are classified together as non-small cell lung cancer (NSCLC), which is responsible for over $80 \%$ of all patients diagnosed with lung cancer.

There are well-established guidelines that suggest therapeutic approaches for non-small cell lung cancer patients ${ }^{3}$. 
Since the last decade, chemotherapy has been recommended as the treatment of choice in order to improve quality of life and prolong survival time for advanced disease. Recent metaanalysis compared outcomes of platinum-based versus single agent chemotherapy for metastatic NSCLC patients, and showed that platinum-based doublets produced higher overall response rate than with single agents. Platinum-based therapy was also associated with a $13 \%$ higher survival rate ${ }^{4}$. Another prospective randomized study ${ }^{5}$ evaluated 1,155 eligible advanced NSCLC patients to compare four different platinum-based regimens of chemotherapy (CDDP+Paclitaxel / CDDP+Gencitabine / CDDP+Docetaxel / Carboplatin+Paclitaxel). The response rate was 19\%, with a median survival time of 7.9 months. The response rate and median survival did not differ among different regimens of chemotherapy, although cisplatin plus gemcitabine was associated with a longer time to progression as well as with higher toxicity. Patients with poor performance status had a significantly lower rate of survival ${ }^{5}$.

Most of these results with chemotherapy derived from rigid protocols that included selected patients and uniform regimens of drugs, performed on clinical-trial settings. However there is a paucity of studies assessing the results of the management of metastatic NSCLC in a routine clinical practice, outside of a controlled clinical trial setting6 .

The aim of this study is to evaluate the usual management of metastatic NSCLC patients outside of a clinical trial setting in three different oncologic centers in Brazil.

\section{PATIENTS AND METHODS}

This is a retrospective study of patients with advanced non-small cell lung cancer admitted for treatment in three different Cancer Centers in Brazil: Hospital do Cancer A C Camargo (HCACC), Sao Paulo; Hospital Amaral Carvalho (HAC), Jau; and Instituto Paulista de Cancerologia (IPC), Sao Paulo. Clinical data were reviewed in the records of these patients from 1990 to 2003. The following criteria were considered to include patients: cytological or histological diagnosis of non-small cell lung cancer; stage IV (central nervous system metastases were included); patients admitted and considered for oncologic treatment according to clinical practice of each institution. Moreover, no patient should have been included in research protocol for treatment.

According to these inclusion criteria, 564 patients were considered for the present study. The following clinical data were obtained by review of the records: age, gender, performance status, site of metastases, weight loss, histological type, chemotherapy regimens and status at last followup. The performance status was determined by ECOG
(Eastern Cooperative Oncology Group) ${ }^{7}$ index, according to clinical data available in the records. Classification of clinical staging was obtained from the records, based on clinical notes or reports of imaging exams (chest, upper abdomen and brain CT, and bone scan). First-line chemotherapy was defined as the first chemotherapeutic approach administered to the patient. According to the coverage of treatment costs, patients were classified in to two groups: Brazilian public heath system and private/health insurance system.

Status of last follow-up was classified as alive without disease, alive with disease, dead from cancer, dead from other causes, and patients who did not return to institution for a period exceeding twice the interval suggested by the assistant physician. Such patients were defined as lost to follow-up.

Statistical analysis: the method of Kaplan-Meier was used to determine actuarial survival ${ }^{8}$. Differences in survival were determined by Breslow and log rank analysis. Overall survival time was defined as the interval between initial diagnosis of NSCLC at each center and the date of last consultation or until death. All statistical analyses were performed with SPSS 10.0 software. The value of $\mathrm{p} \leq 0.05$ was defined as significant.

\section{RESULTS}

The distribution of 564 patients included in the present study according the different oncologic centers was as follow: 39 (7\%) from Instituto Paulista de Oncologia (IPC); $177(31.3 \%)$ from Hospital Amaral Carvalho (HAC), and $348(61.7 \%)$ from Hospital do Cancer A C Camargo (HCACC).

The majority of patients included in the present study were male $(71.5 \%)$ in the sixth to seventh decades of life $(65.1 \%)$. The most common site of metastasis was bone $(32.8 \%)$, and adenocarcinoma was the predominant histologic type $(52.8 \%)$. The characteristics of all patients are showed on Table 1.

Among 564 patients in the present study, 335 (59.4\%) received chemotherapy; the reasons for not treating 229 $(40.6 \%)$ patients were not clearly stated in the records of the patients included in this retrospective study.

The majority $(57.3 \%)$ of treated patients received a combination of two drugs, as shown in Table 2. For all patients, 47 different regimens of chemotherapy were identified. Cisplatin or carboplatin were the most common drugs employed, other frequent drugs are taxanes, vinca alkaloids, gemcitabine and vinorelbine (Table 3). Because of large heterogeneity of drug regimens identified in the present study, we could not classify these different combinations of 
Table 1 - Basic characteristics of patients.

\begin{tabular}{lcc}
\hline $\begin{array}{l}\text { Patients profiles } \\
\text { Age (years) }\end{array}$ & $\mathrm{n}$ & $\%$ \\
\hline $\mathrm{d} \cdot 50$ & 94 & 16.7 \\
$51-70$ & 367 & 65.1 \\
$>71$ & 103 & 18.2 \\
Gender & 403 & 71.5 \\
Male & 161 & 28.5 \\
Female & & \\
\hline
\end{tabular}

\begin{tabular}{lcc}
\hline Performance status (ECOG) & & \\
\hline 0 & 18 & 3.2 \\
1 & 215 & 38.1 \\
2 & 182 & 32.3 \\
3 & 70 & 12.4 \\
No data & 79 & 14.0 \\
\hline
\end{tabular}

\begin{tabular}{lcc}
\hline Metastases & & \\
\hline Bone & 185 & 32.8 \\
Lung & 170 & 30.1 \\
Central Nervous System & 140 & 24.8 \\
Liver & 50 & 8.9 \\
Adrenal & 19 & 3.4 \\
\hline Weight loss & & \\
\hline None & 77 & 13.7 \\
$<10 \%$ & 65 & 11.5 \\
$>10 \%$ & 181 & 32.1 \\
No described & 241 & 42.7 \\
\hline Histology & & \\
\hline Adenocarcinoma & 298 & 52.8 \\
Squamous cells carcinoma & 176 & 31.2 \\
Large cells carcinoma & 90 & 16.0 \\
\hline Total & 564 & 100 \\
\hline NA: notaile.
\end{tabular}

NA: not available.

Table 2 - Characteristics of chemotherapy.

\begin{tabular}{lcc}
\hline Number of drugs & No & $\%$ \\
\hline One & 33 & 9.9 \\
Two & 192 & 57.3 \\
Three & 110 & 32.8 \\
Total & 335 & 100 \\
\hline
\end{tabular}

Table 3 - Drugs used in different regimens of chemotherapy.

\begin{tabular}{lcc}
\hline Drugs & $\mathrm{N}$ & $\%$ \\
\hline Cisplatin / Carboplatin & 280 & 83.5 \\
Taxanes & 64 & 19 \\
Vinca alkaloids & 60 & 18 \\
Gencitabine & 53 & 15.8 \\
Vinorelbine & 45 & 13.4 \\
Others & 225 & 67.1 \\
\hline
\end{tabular}

drugs in comprehensive groups of regimens, so we disclosed all these regimens in Appendix 1. The median number of cycles was four, ranging from one to 13 . The costs of chemotherapy were paid by Brazilian public health system in $49.6 \%$, and by private/health insurance system in $50.4 \%$ of the patients.

The median follow-up time was eight months, and status at last information were as follow: alive without disease: two $(0.3 \%)$ patients; alive with disease: $32(5.6 \%)$ patients; dead from cancer: $415(73.6 \%)$ patients; dead from other causes: 6 (1.1\%) patients, and lost of follow-up: 109 $(19.4 \%)$.

Median overall survival was 8.3 months (CI 95\%: 7.5 - 9.2 months), and overall one-year survival was $37 \%$ (Figure 1). The overall survival was significantly better for patients treated with first line chemotherapy compared to patients that only received best supportive care (Figure 2).

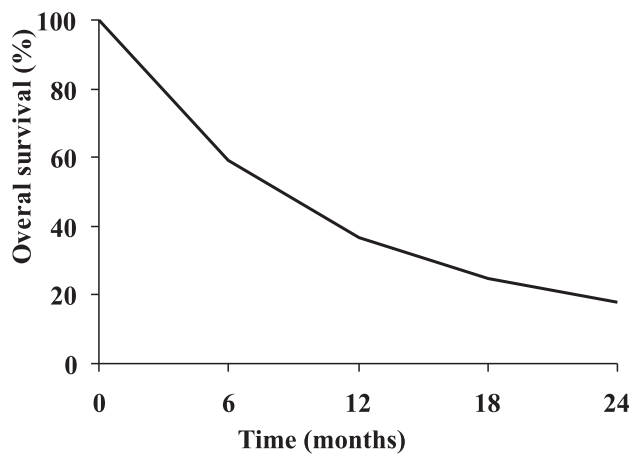

Figure 1 - Overall survival for all patients included in the study.

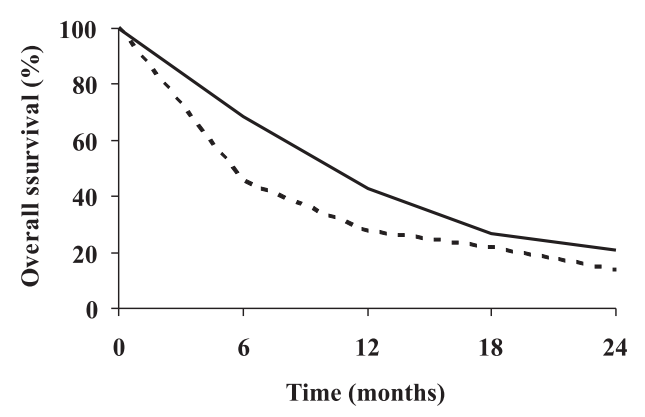

- Chemotherapy $(\mathrm{n}=335)$ - - - - Best supportive care $(\mathrm{n}=229)$

Figure 2 - Overall survival according to treatment of metastatic NSCLC patients $(\mathrm{p}<0.001$ log-rank and Breslow).

\section{DISCUSSION}

Although metastatic lung cancer is associated with a dismal prognosis, systemic treatment can result in improved survival and better quality of life. In the past, the chemotherapy agents more widely used for the tretament of advanced NSCLC were cisplatin, mitomycin, vinblastine and 
etoposide. As single agents, they usually result in response rates varying between $15 \%$ and $25 \%$. Combination regimens included cisplatin plus vinblastine, cisplatin plus etoposide, cisplatin plus vindesine and cisplatin plus vinblastine plus mitomycin (MVP), with response rates ranging from $15 \%$ to $30 \%$, and one-year overall survival from $20 \%$ to $30 \%^{10,11}$. In the last 12 years, new and more effective chemotherapeutic agents, including paclitaxel, docetaxel, gemcitabine, vinorelbine, irinotecan and topotecan, were introduced for the treatment of lung cancer. A meta-analysis of randomized trials showed that platinum-based chemotherapy has been shown to improve median survival by about six weeks, and survival at one year from $5 \%$ to $15 \%{ }^{12}$. Since then, platinum-based chemotherapy has been considered the standard of care for advanced NSCLC patients ${ }^{3,13}$. Moreover there are two other questions regarding the approach of these patients: 1) what is the best combination of drugs in the first-line treatment? 2) What is the optimal duration of treatment? Two recent randomized trials compared different regimens of cisplatin or carboplatin-based chemotherapy and disclosed that there was no difference in response rates or survival ${ }^{5,14}$. According to these trials the following regimens are considered standard of care for advanced NSCLC patients: Cisplatin/ Paclitaxel; Carboplatin/Paclitaxel; Cisplatin/Vinorelbine; Cisplatin/Gemcitabine; Cisplatin/Docetaxel. The duration of chemotherapy was addressed by other randomized trials, and the recommendation is that the duration of firstline chemotherapy should be brief, consisting of three to four cycles or fewer if there is evidence of progressive disease $^{15-17}$.

These recommendations for treating advanced NSCLC patients are mainly defined through rigid protocols of randomized trials. However few reports evaluated the management of metastatic NSCLC patients in community settings. The present study was designed to investigate the regimens and the duration of chemotherapy employed to treat advanced NSCLC patients not included in clinical trials. The three oncologic centers considered in the present survey are reference for oncologic treatment with experienced oncologists. Moreover, two (HCACC and HAC) of these centers have established programs of residency and fellowship in oncology, and have participated in several clinical trials. Clearly this might not exactly reflect the actual management performed in a community setting. On the other hand, considering that all patients are not included in study protocols, the therapeutics approaches are determined according to individual medical decision.

There is little information about the use of chemotherapy for advanced NSCLC patients in the community setting. Recently, Potosky et al reported results indicating that $41 \%$ of stage IV NSCLC patients received chemotherapy as part of their initial treatment in a population based sample of NSCLC patients in the United States of America, in $1996^{6}$. However, the authors did not analyze in detail the regimens of chemotherapy that were employed. Other studies confirmed that the rate of patients who received chemotherapy for metastatic NSCLC has been increasing over recent decades, and that authors have found that nonclinical factors (age, race or ethnicity and hospital type) influenced the decision making process of choosing therapeutic approach for NSCLC patients ${ }^{18}$. In the present study we found that $59.1 \%$ of patients received chemotherapy, but our aim was to evaluate how they were treated rather than the population that actually was selected for each treatment.

Considering the patients that were submitted to chemotherapy, we identified 47 different regimens of drugs employed as first-line treatment, in spite of randomized clinical trials recommending few combinations of drugs for advanced NSCLC ${ }^{19}$. Within this heterogeneity of drug regimens we observed that the majority of the patients received combinations of two drugs $(57.3 \%)$, cisplatin or carboplatin was present in $83.5 \%$ of the treated patients, and the median number of cycles was four, as recommended by prospective trials addressing this issue $e^{13,20}$. However, almost one third of the patients received combinations of three drugs (Table 2), and $67.1 \%$ of the patients were treated with drugs not usually employed in regimens of first-line chemotherapy (Table 3), both in disagreement with the recommendation from prospective trials. Moreover, some patients received $13 \mathrm{cy}-$ cles of chemotherapy while prospective trials recommended three to four cycles. Although the majority of patients received adequate treatment, there was a great heterogeneity in the regimens of drugs to treat metastatic NSCLC patients in our community-based in cohorts of patients (see Apendix 1). Because of the variability of drugs employed we could not analyze the reasons why different combinations were used, but we can hypothesize the following reasons: 1) the inclusion of patients began in 1990, before platinum-based chemotherapy came to be considered the standard of the care for metastatic NSCLC patients; 2) some of the patients (49.6\%) came from public health system and this could create some restrictions to the use of several regimens of chemotherapy; 3 ) in the period of 13 years different oncologists treated patients in the oncologic centers.

Due to the wide heterogeneity of chemotherapeutic regimens employed to treat the patients included in the present study, we expected that survival would be different from observed in the published prospective randomized trials. However the overall median survival of our patient population submitted to chemotherapy was 9.7 months. Schiller et al studied four different regimens of platinum-based chemo- 
therapy for advanced NSCLC patients and observed that there were no significant differences in survival between different regimens of chemotherapy, with median survival ranging from 7.4 to 8.1 months among different combinations of drugs ${ }^{5}$. In the last few years, other randomized clinical trial disclosed equally poor survival for patients with advanced NSCLC treated with platinum-based chemotherapy, with a median survival ranging from 8 to 10 months $^{21}$. To our surprise, the overall survival observed in the present study is quite similar to that showed by prospective randomized trials with adequate platinum-based chemotherapy. Many patients (19.4\%) were lost from follow-up, as expected in a retrospective population-based study. Moreover, staging methods and images were not uniform among the centers included in the present study, as opposed to strict randomized trials. Both characteristics could explain, partially the survival rates observed in our study.
Irrespective to the regimen, there was a significant advantage for the group treated with chemotherapy as compared to the group of patients that only received best supportive care (Figure 2). However as a result of a nonrandomized study this difference of survival might reflect a selection bias of patients with better prognosis to receive chemotherapy.

Despite the limitation of a retrospective review, this is the first study to describe the widespread heterogeneity in the management of metastatic NSCLC patients out of a clinical trial, in the Brazilian population. This heterogeneity is mainly due to a great variability in combination of chemotherapeutic regimens, some of them not tested in randomized trials. Results of prospective randomized clinical trials for metastatic NSCLC patients should be carefully analyzed and transferred to the daily clinical practice according to the reality of each center of oncologic treatment.

\section{RESUMO}

Naime FF, Younes RN, Kersten BG, Anelli A, Beato CAM, Andrade RM, Carrara MP, Gross JL. Câncer de pulmão não pequenas células metastático: Heterogeneidade do tratamento na prática clínica de rotina no Brasil. Clinics. 2007;62(4):397-404.

INTRODUÇÃO: O câncer de pulmão é uma das principais causas de morte relacionadas ao câncer. Aproximadamente três quartos destes tumores são carcinoma não pequenas células. Ao diagnóstico, a maioria dos pacientes se apresenta com doença avançada localmente ou metastática. A quimioterapia é o tratamento de escolha para pacientes com câncer de pulmão em estadiamento avançado. A mai- oria dos estudos publicados com quimioterapia é realizada em centros acadêmicos sob controle rígido de protocolos de pesquisa.

OBJETIVO: O objetivo deste estudo é avaliar os resultados do tratamento rotineiro de pacientes com carcinoma de pulmão não pequenas células metastático, fora de protocolos de pesquisa clínica em três centros oncológicos brasileiros.

MÉTODO: Trata-se de um estudo retrospectivo de pacientes com câncer de pulmão não pequenas células metastático, admitidos para tratamento em três diferentes centros oncológicos no Brasil. Foram avaliados 564 pacientes neste estudo provenientes do sistema de saúde público e privado. 
RESULTADOS: Dentre os 564 pacientes deste estudo, 335 $(59,4 \%)$ receberam quimioterapia. Considerando todos os pacientes, foram identificados 47 esquemas diferentes de quimioterapia. O tempo médio de seguimento foi de oito meses e a sobrevida global mediana de todos os pacientes submetidos à quimioterapia foi de 9,7 meses.

DISCUSSÃO: Havia uma grande heterogeneidade de esquemas de drogas para o tratamento de pacientes com câncer de pulmão não pequenas células metastático. A sobrevida global foi significativamente melhor para paci- entes tratados com quimioterapia de primeira linha comparado com pacientes que receberam somente tratamento de suporte clínico. Resultados de estudos clínicos prospectivos randomizados deverão ser cuidadosamente analisados antes de serem transferidos para a prática clínica diária.

UNITERMOS: Câncer de pulmão. Câncer de pulmão não pequenas células (CPNPC). Metástases. Quimioterapia. Prática clínica de rotina
1. Jemal A, Siegel R, Ward E, Murray T, Xu J, Smigal C, et al. Cancer statistics, 2006. CA Cancer J Clin. 2006;56(2):106-30.

2. Intituto Nacional do Cancer. Estimativas 2006. Incidência de cancer no Brasil. Avaiable at:www.inca.gov.br/estimativa/2006/ index.asp?link=conteudoview.asp\&ID=5. AcessedNovember7,2006.

3. National Cancer Institute. Non-small cell lung cancer (PDQ®): treatment. Avaiable at: www.cancer.gov/cancertopics/pdq/treatment/non-small-celllung/healthprofessional. AcessedNovember7, 2006.

4. Hotta K, Matsuo K, Ueoka H, Kiura K, TabataM, Tanimoto M. Addition of platinum compounds to a new agent in patients with advanced nonsmall-cell lung cancer: a literature based meta-analysis of randomised trials. Ann Oncol. 2004;15(12):1782-9.
5. Schiller JH, Harrington D, Belani CP, Langer C, Sandler A, Krook J et al. Comparison of four chemotherapy regimens for advanced non-smallcell lung cancer. N Engl J Med. 2002;346(2):92-8.

6. Potosky AL, Saxman S, Wallace RB, Lynch CF. Population variations in the initial treatment of non-small-cell lung cancer. J Clin Oncol. 2004;22(16):3261-8.

7. Oken MM, Creech RH, Tormey DC, Horton J, Davis TE, McFadden ET, et al.Toxicity and response criteria of the Eastern Cooperative Oncology Group. Am J Clin Oncol. 1982;5(6):649-55.

8. Kaplan ZL, Meier P. Nonparametric estimation from incomplete observation. J Am Stat Assoc 1958;53:457-81. 
9. Bunn PA, Jr, Kelly K. New chemotherapeutic agents prolong surviva and improve quality of life in non-small cell lung cancer: a review of the literature and future directions. Clin Cancer Res 1998; 4:1087-100.

10. Bonomi PD, Finkelstein DM, Ruckdeschel JC, et al. Combination chemotherapy vs single agents followed by combination chemotherapy in stage IV non-small-cell lung cancer: a study of the Eastern Cooperative Oncology Group. J Clin Oncol 1989; 7:1602-13.

11. Weick JK, Crowley J, Natale RB, et al. A randomized trial of five cisplatin-containing treatments in patients with metastatic non-smallcell lung cancer: a Southwest Oncology Group study. J Clin Oncol 1991; 9:1157-62.

12. Non-small Cell Lung Cancer Collaborative Group. Chemotherapy in non-small cell lung cancer: a meta-analysis using updated data on individual patients from 52 randomized clinical trials. BMJ. 1995;311(7010):899-909.

13. National Comprehensive Cancer Network. Practice Guidelines in Oncology. Non-small Cell Lung Cancer. Available at: www.ncen.org/ professional/ physicians/nsclc.pdf. Acessed November 8, 2006.

14. Kelly K, Crowley J, Bunn PA Jr, Presant CA, Grevstad PK, Moinpour $\mathrm{CM}$, et al.Randomized phase III trial of paclitaxel plus carboplatin versus vinorelbine plus cisplatin in the treatment of patients with advanced non-small-cell lung cancer: a Southwest Oncology Group trial. J Clin Oncol. 2001;9(13):3210-8.

15. Smith IE, O'Brien ME, Talbot DC, Nicolson MC, Mansi JL, Hickish TF, et al. Duration of chemotherapy in advanced non-small-cell lung cancer: a randomized trial of three versus six courses of mitomycin, vinblastine, and cisplatin J Clin Oncol. 2001;19(5):1336-43.
16. Socinski MA, Schell MJ, Peterman A, Bakri K, Yates S, Gitten R, et al. Phase III trial comparing a defined duration of therapy versus continuous therapy followed by second-line therapy in advanced-stage IIIB/IV nonsmall-cell lung cancer. J Clin Oncol. 2002;20(5):1335-43.

17. von Plessen C, Bergman B, Andresen O, Bremnes RM, Sundstrom S, Gilleryd M, et al. Palliative chemotherapy beyond three courses conveys no survival or consistent quality-of-life benefits in advanced non-smallcell lung cancer. Br J Cancer. 2006;95(8):966-73.

18. Earle CC, Venditti LN, Neumann PJ, Gelber RD, Weinstein MC, Potosky $\mathrm{AL}$, Weeks JC. Who gets chemotherapy for metastatic lung cancer? Chest. 2000;117(5):1239-46.

19. Alberola V, Camps C, Provencio M, Isla D, Rosell R, Vadell C et al. Cisplatin plus gemcitabine versus a cisplatin-based triplet versus nonplatinum sequential doublets in advanced non-small-cell lung cancer: a Spanish Lung Cancer Group phase III randomized trial. J Clin Oncol. 2003;21(17):3207-13.

20. Smith IE, O'Brien ME, Talbot DC, Nicolson MC, Mansi JL, Hickish TF, et al. Duration of chemotherapy in advanced non-small-cell lung cancer: a randomized trial of three versus six courses of mitomycin, vinblastine, and cisplatin J Clin Oncol. 2001;19(5):1336-43.

21. Stinchcombe TE, Lee CB, Socinski MA. Current approaches to advanced-stage non-small-cell lung cancer: first-line therapy in patients with a good functional status. Clin Lung Cancer. 2006; 7 Suppl 4:S1117. 
Appendix 1 - Different drug combinations employed to treat metastatic NSCLC.

\begin{tabular}{|c|c|c|c|c|c|}
\hline Chemotherapy profiles & IPC n 26 & $\mathrm{H} \mathrm{C}$ n 167 & H Jaún 142 & Total n 335 & $\%$ \\
\hline Cisplatin+doxorucicin+ciclofosfamide & 1 & 0 & 37 & 38 & 11.3 \\
\hline Cisplatin+etoposide & 1 & 12 & 22 & 35 & 10.4 \\
\hline Carboplatin+paclitaxel & 6 & 23 & 3 & 32 & 9.6 \\
\hline Cisplatin+gemcitabine & 2 & 9 & 21 & 32 & 9.6 \\
\hline MVP(mitomycin+vinblastine+cisplatin) & 2 & 20 & 0 & 22 & 6.6 \\
\hline Cisplatin+vinorelbine & 2 & 12 & 2 & 16 & 4.8 \\
\hline Carboplatin+etoposide & 2 & 1 & 11 & 14 & 4.2 \\
\hline Paclitaxel+vinorelbine+carboplatin & 0 & 14 & 0 & 14 & 4.2 \\
\hline Cisplatin+ifosfamide+vinblastine & 0 & 11 & 0 & 11 & 3.3 \\
\hline Cisplatin+farmorubicina+ciclofosfamide & 1 & 4 & 6 & 11 & 3.3 \\
\hline Cisplatin +5 fluoruracil & 0 & 0 & 10 & 10 & 3 \\
\hline Gemcitabine & 0 & 9 & 1 & 10 & 3 \\
\hline Cisplatin+vinblastine & 0 & 8 & 1 & 9 & 2.7 \\
\hline Gemcitabine+vinorelbine & 3 & 4 & 0 & 7 & 2.1 \\
\hline Etoposide po & 1 & 0 & 6 & 7 & 2.1 \\
\hline Docetaxel & 0 & 6 & 0 & 6 & 1.8 \\
\hline Carboplatin+docetaxel & 2 & 3 & 1 & 6 & 1.8 \\
\hline Vinorelbine & 0 & 5 & 0 & 5 & 1.5 \\
\hline Mitomycin+vinblastine & 0 & 3 & 1 & 4 & 1.2 \\
\hline Vincristin+doxorubicin+ciclofosfamide & 0 & 4 & 0 & 4 & 1.2 \\
\hline Ciclofosfamide+etoposide & 0 & 0 & 4 & 4 & 1.2 \\
\hline Chemotherapy profiles & IPC n 26 & H C n 167 & H Jaún 142 & No total n 335 & $\%$ \\
\hline Cisplatin+docetaxel & 0 & 1 & 2 & 3 & 0.9 \\
\hline Gemcitabine+carboplatin & 1 & 0 & 2 & 3 & 0.9 \\
\hline Ciclofosfamide+epirrubicina+vincristin & 0 & 0 & 2 & 2 & 0.6 \\
\hline Cisplatin+paclitaxel & 1 & 1 & 0 & 2 & 0.6 \\
\hline Vincristin + methotrexate + ciclofosfamide & 0 & 2 & 0 & 2 & 0.6 \\
\hline Vincristin+etoposide & 0 & 2 & 0 & 2 & 0.6 \\
\hline Cisplatin & 0 & 1 & 1 & 2 & 0.6 \\
\hline Carboplatin weekly & 0 & 1 & 1 & 2 & 0.6 \\
\hline Ciclofosfamide+methotrexate & 0 & 2 & 0 & 2 & 0.6 \\
\hline Carboplatin+vinorelbine & 0 & 2 & 0 & 2 & 0.6 \\
\hline Ifosfamide+carboplatin+vinblastine & 0 & 1 & 0 & 1 & 0.3 \\
\hline Carboplatin +5 fluoruracil & 0 & 0 & 1 & 1 & 0.3 \\
\hline Carboplatin+ciclofosfamide+etoposide & 0 & 1 & 0 & 1 & 0.3 \\
\hline Gemcitabine+docetaxel & 1 & 0 & 0 & 1 & 0.3 \\
\hline Paclitaxel & 0 & 1 & 0 & 1 & 0.3 \\
\hline Mitomycin+vinblastine+carboplatin & 0 & 1 & 0 & 1 & 0.3 \\
\hline Fluoruracil+doxorubicin+ciclofosfamide & 0 & 1 & 0 & 1 & 0.3 \\
\hline Methotrexate & 0 & 1 & 0 & 1 & 0.3 \\
\hline Cisplatin+epirrubicin & 0 & 0 & 1 & 1 & 0.3 \\
\hline Ciclofosfamide+epirrubicin & 0 & 0 & 1 & 1 & 0.3 \\
\hline Carboplatin+ciclofosfamide & 0 & 0 & 1 & 1 & 0.3 \\
\hline Chemotherapy profiles & IPC n 26 & H C n 167 & H Jaún 142 & No total n 335 & $\%$ \\
\hline Uft & 0 & 0 & 1 & 1 & 0.3 \\
\hline Carboplatin+ciclofosfamide+vinblastine & 0 & 0 & 1 & 1 & 0.3 \\
\hline Carboplatin+vinblastine & 0 & 0 & 1 & 1 & 0.3 \\
\hline Gemcitabine+etoposide & 0 & 0 & 1 & 1 & 0.3 \\
\hline Ifosfamide+mitexan+vinblastine & 0 & 1 & 0 & 1 & 0.3 \\
\hline
\end{tabular}

